\title{
Die JOT-Multimedia-Story: Schichtdickenmessung
}

\author{
Zum Firmenjubiläum von Coatmaster hat die JOT-Redaktion rund um das Thema berührungslose \\ Schichtdickenmessung eine multimediale Story kreiert. Erfahren Sie per "Scrollytelling“" mehr über \\ die ATO-Technologie und verfügbare Lösungen. Den Abschluss macht eine unterhaltsame Reise in \\ die Firmenhistorie.
}

\section{Hier geht's zur Story: https://go.sn.pub/JOT1221}

Vor 10 Jahren fiel bei Coatmaster der Startschuss. Anfangs noch unter einem anderen Firmennamen begannen die Gründer Andor Bariska und Prof. Dr. Nils A. Reinke Geräte für eine berührungslose Schichtdickenmessung zu entwickeln. Das Messprinzip basiert auf der ATO-Technologie (Advanced Thermal Optics), die weltweit patentiert wurde. Zum Jubiläum von Coatmaster hat die JOT-Redaktion - anstelle des klassischen Print-Artikels - eine multimediale Story kreiert: „10 Jahre berührungslose Schichtdickenmessung“

\section{Storytelling in seiner modernsten Form}

Dort, wo das klassische Print-Magazin an seine Grenzen stößt, bietet die JOT-Multimedia-Story viele weitere Möglichkeiten: Interaktives Storytelling mit vielfältigen multimedialen Inhalten wie Bildergalerien, Videos, Links, Whitepaper, Buttons und weiteren Funktionalitäten. Alles redaktionell leicht verständlich aufbereitet und charmant verpackt. So geht Infotainment heute!

\section{Interaktiv und unterhaltsam auf allen Geräten}

Mit dem Mausrad am Desktop oder per Gestensteuerung auf dem Touchscreen von Smartphone oder Tablet können sich Nutzerinnen und Nutzer durch die Story scrollen oder wischen. Sie entscheiden selbst, mit welcher Geschwindigkeit und Infor-

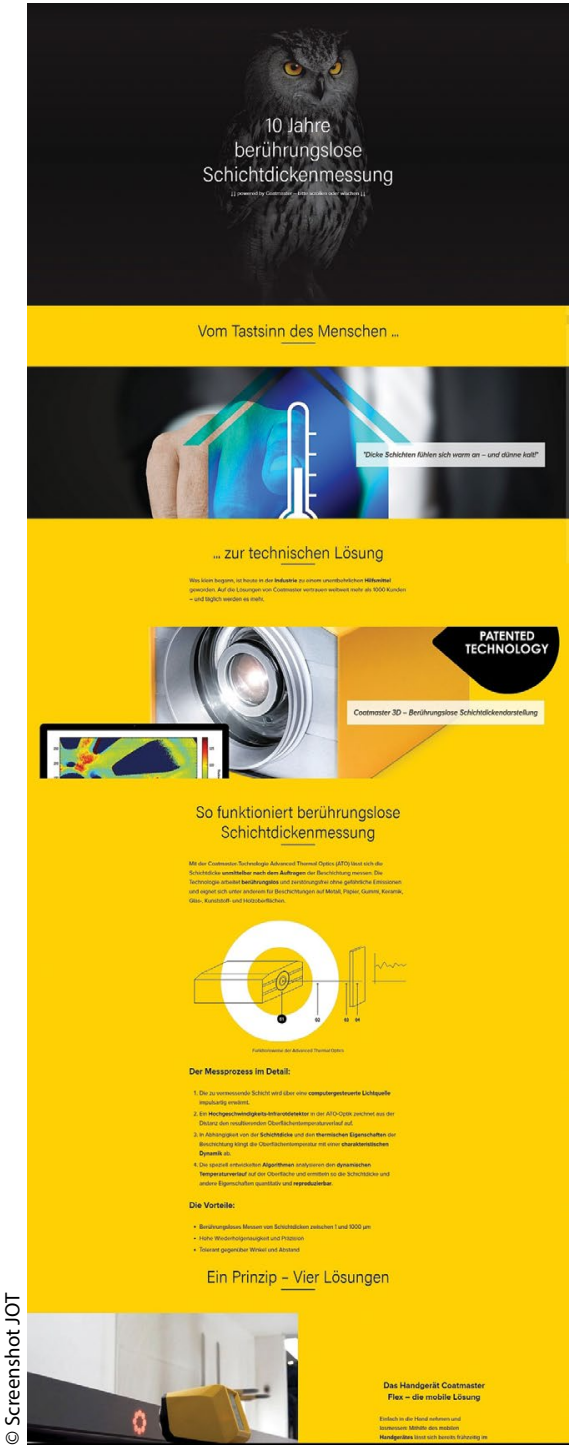

Die JOT-Multimedia-Story hier ein kleiner Ausschnitt verspricht interaktives Storytelling per Mausrad oder Wisch-Geste.

mationstiefe sie sich dem Thema widmen, welches Video sie sich anschauen, welchem weiterführenden Link sie folgen oder welche Zusatzinfos sie sich herunterladen. Die JOT-Multimedia-Story läuft auf jedem Gerät mit Webbrowser und ist responsiv gestaltet. Das bedeutet, dass sich die Darstellung auf die Eigenschaften des Endgeräts anpasst. Je nachdem ob PC, Smartphone oder Tablet und abhängig vom Format (hoch/quer) sowie der Displayauflösung werden die Inhalte angepasst. So kann es etwa auf dem Smartphone im Hochformat durchaus mal passieren, dass Bilder teilweise seitlich beschnitten sind. In dem Fall brauchen Sie Ihr Gerät einfach nur quer zu halten, und schon sollte das Problem behoben sein. //

(Sey)

Die JOT-Redaktion wünscht viel Spaß! https://go.sn.pub/JOT1221

\section{Kontakt}

coatmaster AG

Winterthur (Schweiz)

info@coatmaster.com

www.coatmaster.com 